\title{
Cardiac Sympathetic Activity and Left Ventricular Dyssynchrony
}

\author{
- An Old and New Issue -
}

\author{
Shinichi Fujimoto, MD, PhD
}

C ardiac sympathetic activity in the failing heart is both an old and a new issue. Classically in the heart, sympathetic activation results in an increased heart rate, more forceful contraction, and enhanced atrioventricular conduction, whereas the primary effect of the parasympathetic system is on heart rate regulation. Patients with heart failure show activation of the sympathetic nerve system, as reflected by increased plasma norepinephrine levels. As a consequence, a higher concentration of norepinephrine is present in the sympathetic cleft, leading to chronic stimulation and downregulation of myocardial $\beta$-adrenoceptors. Many studies ${ }^{1-3}$ have shown that the loss of normal sympathetic control over myocardial function is associated with an increased incidence of adverse outcomes such as the development and progression of heart failure and the occurrence of critical arrhythmias that often cause sudden cardiac death. In general, neuronal uptake of norepinephrine is impaired in the failing myocardium. ${ }^{123} \mathrm{I}-$ MIBG has become known as a reliable indicator of cardiac sympathetic activity and in this issue of the Journal, Tanaka et al clearly show that decreased uptake of MIBG is associated with dyssynchrony and successful response to cardiac resynchronization therapy (CRT) ${ }^{4}$

\begin{tabular}{l} 
Article p382 \\
\hline Dyssynchrony is associated with not only the electrical \\
conduction system but also myocardial mechanical contrac- \\
tion. In that sense, patients in the study by Tanaka et al had \\
wide QRS duration ( $>120 \mathrm{~ms}$ ). I suppose that this is a very \\
important point because those patients must have electrome- \\
chanical dyssynchrony in their myocardial cells. Xiao et al \\
previously reported that patients with dilated cardiomyopathy \\
(DCM) show prolonged QRS activation time on signal-aver- \\
aged ECG, with a long PR interval, and these findings are \\
closely associated with their prognosis.5, Underlying low- \\
voltage contraction activity, previously referred to as "early \\
potential", causes a prolonged PR interval, because ventricu- \\
lar activation under low-voltage conditions is cut out by the \\
filter function of the ECG. Dyssynchrony is also related to \\
a prolonged QRS activation time. Therefore, dyssynchrony \\
on echocardiography in DCM is also a phenomenon of pro- \\
longed electromechanical, nonuniform ventricular activation. \\
This nonuniform ventricular activation may be caused by myo-
\end{tabular}

cardial injury, showing as decreased sympathetic activity on MIBG scintigraphy in the report by Tanaka et al. ${ }^{4}$

On the other hand, contraction delay leads to low cardiac output, and may also increase systemic sympathetic activity and cause downregulation of myocardial cells. This must cause the reduced sympathetic activity in the myocardium on MIBG. We cannot distinguish such an effect using Doppler echocardiography. This is also an unsolved problem.

For CRT in DCM, dyssynchrony in the ventricle is estimated as the electromechanical coupling time by Doppler echocardiography. ${ }^{7}$ But such time intervals include delays in both electrical conduction time and myocardial mechanical contraction. An MIBG scintigraphic abnormality may reflect both phenomena. When considering the conduction delay in the dyssynchrony observed in DCM, we need to adjust not only the electrical delay caused by CRT, but also the mechanical contraction delay caused by medical treatment. ${ }^{8-12}$

LV filling time is also an important factor for dyssynchrony. Brecker et al reported that patients with a short filling time are good candidates for CRT. ${ }^{13}$ We need to emphasize more the importance of the LV filling time in DCM as an indication for CRT.

As the next step, we need to investigate the recovery of sympathetic activity on MIBG scintigraphy after CRT and medical treatment.

\section{References}

1. Brunner-La Rocca HP, Esler MD, JenningsGL, Kay DM. Effect of cardiac nervous activity on mode of death in congestive heart failure. Eur Heart J 2001; 22: 1136-1143.

2. Cohn JN, Levine TB, Olivari MT, Garberg V, Lura D, Francis GS, et al. Plasma norepinephrine as a guide to prognosis in patients with chronic congestive heart failure N Engl J Med 1984; 311: 819-823.

3. Leimbach WN Jr, Wallin BG, Victor RG, Aylward PE, Sundlof G, Mark AL. Direct evidence from intraneural recordings for increased central sympathetic outflow in patients with heart failure. Circulation 1986; 73: 913-919.

4. Tanaka H, Tatsumi K, Fujiwara S, Tsuji T, Kaneko A, Ryo K, et al. Effect of left ventricular dyssynchrony on cardiac sympathetic activity in heart failure patients with wide QRS duration. Circ J 2012; 76: $382-389$.

5. Xiao HB, Roy C, Gibson DG. Nature of ventricular activation in patients with dilated cardiomyopathy: Evidence for bilateral bundle branch block. Heart 1994; 72: 167-174.

6. Xiao HB, Roy C, Fujimoto S, Gibson DG. Natural history of abnormal conduction and its relation to prognosis in patients with dilated

The opinions expressed in this article are not necessarily those of the editors or of the Japanese Circulation Society.

Received November 25, 2011; accepted November 25, 2011; released online December 17, 2011

Center for Education Development, Nara Medical University, Kashihara, Japan

Mailing address: Shinichi Fujimoto, MD, PhD, General Medicine, Nara Medical University, 840 Shijo, Kashihara 634-8522, Japan.

E-mail: sfujimot@naramed-u.ac.jp

ISSN-1346-9843 doi:10.1253/circj.CJ-11-1377

All rights are reserved to the Japanese Circulation Society. For permissions, please e-mail: cj@j-circ.or.jp 
cardiomyopathy. Int J Cardiol 1996; 53: $163-170$.

7. Chung R, Sutton R, Henein MY. Beyond dyssynchrony in cardiac resynchronization therapy. Heart 2008; 94: 991-994.

8. Cohn JN, Tognoni G; Valsartan Heart Failure Trial Investigators. A randomized trial of the angiotensin-receptor blocker valsartan in chronic heart failure. N Engl J Med 2001; 345: 1667-1675.

9. Tsutamoto T, Sakai H, Ibe K, Yamaji M, Kawahara C, Nakae I, et al. Effect of atorvastatin vs. rosuvastatin on cardiac sympathetic nerve activity in non-diabetic patients with dilated cardiomyopathy. Circ J 2011; 75: 2160-2166.

10. Tsutamoto T, Tanaka T, Sakai H, Nishiyama K, Fujii M, Yamamoto $\mathrm{T}$, et al. Beneficial effect of perindopril on cardiac sympathetic nerve activity and brain natriuretic peptide in patients with chronic heart failure: Comparison with enalapril. Circ J 2008; 72: 740-746.

11. Harada K, Nomura M, Nishikado A, Uehara K, Nakaya Y, Ito S. Clinical efficacy of efonidipine hydrochloride, a T-type calcium channel inhibitor, on sympathetic activities. Circ J 2003; 67: 139-145.

12. Hara Y, Hamada M, Ohtsuka T, Ogimoto A, Saeki H, Suzuki J, et al. Use of thallium-201 myocardial scintigraphy for the prediction of the response to $\beta$-blocker therapy in patients with dilated cardiomyopathy. Circ J 2002; 66: 1139-1143.

13. Brecker SJD, Xiao HB, Sparrow J. Effect of dual-chamber pacing with short atrioventricular delay in dilated cardiomyopathy. Lancet 1992; 340: 1308-1312. 